\title{
Comparative experimental study of the mechanical and fracture properties of Portland limestone and Corsehill sandstone
}

\author{
Aikaterini Marinelli, Matthew R. Stewart \\ School of Engineering and the Built Environment, Edinburgh Napier University, EH10 5DT Edinburgh, Scotland \\ A.Marinelli@napier.ac.uk, bttp://orcid.org/0000-0003-3769-2509
}

\begin{abstract}
An experimental investigation of the mechanical and fracture characteristics of Portland limestone and Corsehill sandstone is undertaken, aiming at enhancing understanding of the structural behaviour of these natural building stones commonly used in both new and restoration projects in Edinburgh, Scotland. A series of three-point bending and four-point bending tests on appropriately cut prismatic samples, in the presence of U-shape notches, were performed and results were interpreted following the concepts of crack mouth opening displacement and fracture energy. The critical crack opening displacement could be further investigated as a fracture criterion, independently of the method used for its determination. At a second stage, the effect of specimen shape and size on flexural strength, deflection at mid-span, crack mouth opening displacement and fracture energy was studied for Portland limestone. Despite the scattering of results, trends observed comprise (a) the negative correlation between the flexural strength of Portland limestone and the specimen span length and (b) the positive correlation between fracture energy and specimen size. Conclusions drawn are in good agreement with similar ones for other quasi-brittle materials and contribute to the assessment of the fracture behaviour of full size structural members that are often beyond the range of possible failure testing.
\end{abstract}

KEYwORDS. Corsehill sandstone; Portland limestone; Mechanical properties; Size effect; Shape effect; Fracture energy.

\section{OPEN ACCESS}

Citation: A. Marinelli., M. R. Stewart, Comparative experimental study of the mechanical and fracture properties of Portland limestone and Corsehill sandstone, Frattura ed Integrità Strutturale, 50 (2019) 438-450.

Received: 16.01.2019

Accepted: 15.05 .2019

Published: 01.10.2019

Copyright: (C) 2019 This is an open access article under the terms of the CC-BY 4.0 which permits unrestricted use, distribution, and reproduction in any medium, provided the original author and source are credited.

\section{INTRODUCTION}

$\mathrm{H}$ istorical buildings and monuments reflect not only the significance of cultural heritage but also indicate the diversity of civilizations, showing the history of the past while revealing local identities. The built heritage has formed the foundation of many successful regeneration projects in many cities across the United Kingdom (UK). Local historic buildings add to the unique character of a region, help to promote a sense of community and have a significant part in creating a sense of place and differentiation. These places of cultural significance must be conserved for present and future generations in accordance with the principle of inter-generational equity [1]. 
Cultural heritage is among the priceless and irreplaceable assets, not only of each nation, but of humanity as a whole [2]. Since ancient times, natural building stone has been employed as primary construction material for a wide range of different structures, from massive aqueducts and bridges to simple walls and columns. The rehabilitation and conservation of historic stone masonry buildings is a matter of great importance around the world, as it is related with the need to improve and extend the life of a structure for new conditions of use while protecting our cultural heritage.

Scotland's historic environment is an essential part of the country's cultural background and its economy. Scotland has a long history of building with stone and is one of the countries with the richest legacies of traditional and historic buildings in the UK, with around 450,000 traditionally constructed buildings including castles, bridges, dwelling houses and churches [3]. Some of these are internationally iconic structures of historical and cultural heritage.

The city of Edinburgh is an excellent showcase of natural building stone's use as a construction material, being extensively utilized since the early 11th century and earning the city the alias 'the Grey Athens of the North' (Fig. 1).

Various types of sandstone, such as Dunhouse, Corsehill and Craigleith, were easily available due to the abundance of quarries located locally in the Lothians and Fife [4]. Eventually, during the construction of the 'New Town' district of Edinburgh from the $18^{\text {th }}$ to the $20^{\text {th }}$ century, the local sandstone supplies became exhausted paving the way for new types of stone to be imported into the city from further afield in Britain, such as limestone, granite and dolerite. This added further depth to the architecture of the city (Fig.2a,b). Nowadays, of the roughly twenty quarries in Scotland, eight are currently producing dimensioned sandstone and six are producing flagstone (laminated, fine-grained sandstone suitable for paving). Since the conclusion of World War 1, the use of natural building stone as a primary construction material declined in place of cheaper, easier to produce materials such as concrete [5]. However, in the past thirty years, there has been a revival in the use of natural building stone, attributed to both architectural requirements and public yearning for buildings that are not just functional but also aesthetically pleasing, with the National Museum of Scotland (Fig.2c) and the Scottish Widows building being great such examples of modern structures. Still though, nowadays most projects involving natural building stones in Edinburgh are restoration projects, presenting challenges regarding diagnosis and conservation due to the variability of the mechanical and physical properties of masonry components, their complex geometry and construction techniques, the deterioration level and the lack of historical technical documentation.
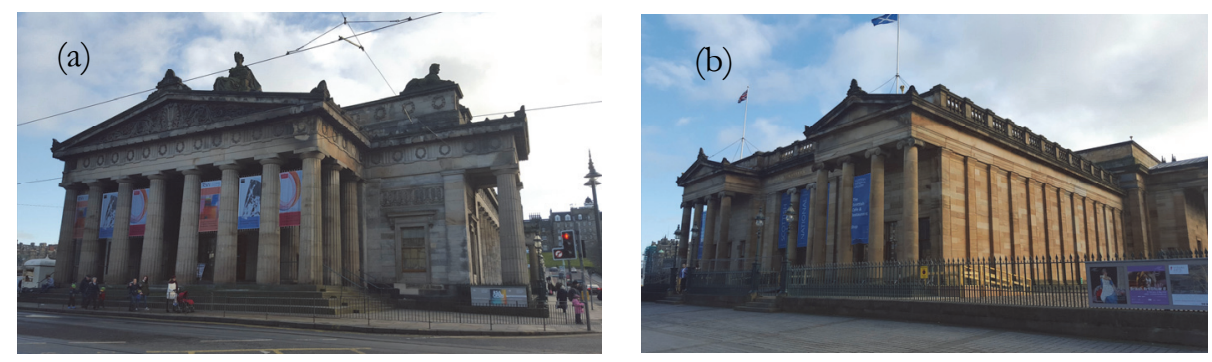

Figure 1: (a) National Gallery; (b) Royal Scottish Academy, The Mound.
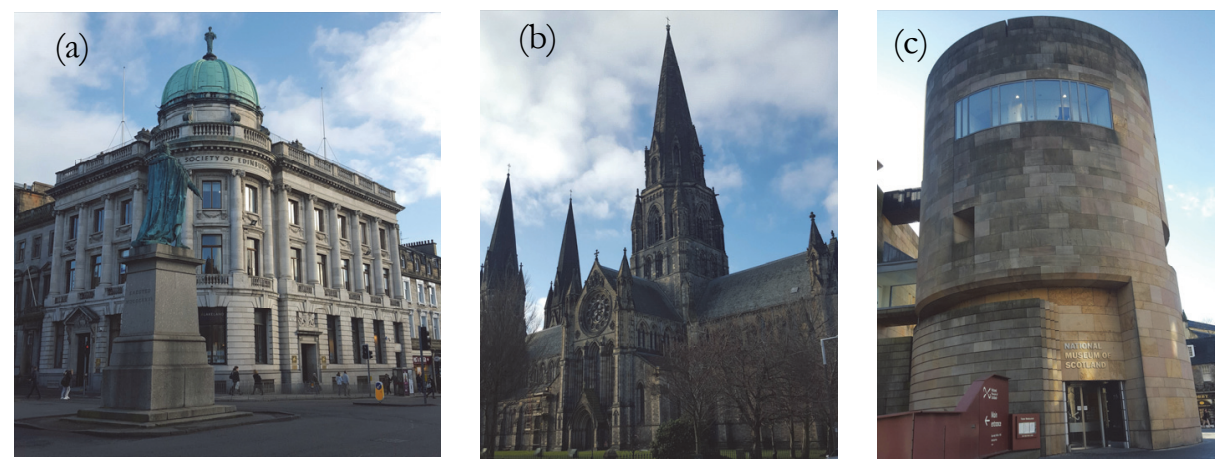

Figure 2: (a) The Royal Society of Edinburgh; (b) St. Mary's Cathedral; (c) National Museum of Scotland.

Design concepts for projects involving natural building stones are largely based on the ultimate strength of materials. The possibility of introducing alternative criteria on the basis of linear fracture mechanics concepts, taking into account the brittleness of the natural building stone and the presence of cracks in it, is examined for the case of two commonly used in Edinburgh such stones: the 'Grove Whitbed' Portland limestone and the Corsehill sandstone. At a first stage, for the 
purpose of definition of failure criteria for these stones used in new as well as in restoration projects, their mechanical behaviour and fracture characteristics are experimentally investigated by performing standard compressive tests, as well as three-point bending (3PB) and four-point bending (4PB) tests on appropriately cut prismatic samples, in the presence of U-shape notches and following the concepts of crack mouth opening displacement (CMOD) and fracture energy [6,7].

Furthermore, it is observed that the geometry and the shape of specimens proposed by standards relevant to brittle geomaterials differ, concerning both their shape and size. In any case, laboratory space and equipment restrictions together with prohibitive costs for large scale testing, make the design of large elements and structures dependent inevitably on extrapolation from test results on much smaller laboratory specimens.

Design codes do not yet include explicit guidance regarding the transition from laboratory results based on smaller scale specimens to parameters suitable for the design of full size structural elements. This is attributed to the - evident in the literature - lack of unanimous scientific approach and generally accepted theory concerning the laws governing this transition, making regulatory bodies reluctant to change currently used empirical or semi-empirical formulas based on curve fitting to the experimental results [8].

Interest in the size effect goes many centuries back, with the observation that the nominal strength of structural elements changes by scaling their size been made by Leonardo Da Vinci [9]. The primal scaling idea by Galileo [10] introducing the concepts of stress and strength was much later soundly questioned by the statistical weakest-link theory by Fisher and Tippett [11], further developed by Weibull [12]. Limitations to the use of the statistical approach were posed due to discrepancies emerging from various experiments first conducted in concrete by Walsh [13]. Nowadays, two approaches are widely encountered in the literature: the deterministic energetic theory by Bazant [14], based on the observation that failure of quasi-brittle materials is characterized by both energy and stress quantities and the theory of crack fractality as described by Carpinteri [15] and Carpinteri et al. [16], associating the size effect with the fractal nature of crack surfaces.

In this context and based on the results of the first stage of this investigation on both materials, a second stage of the study focuses on the influence of specimen shape and size on the mechanical and fracture behaviour of Portland limestone only. Consideration of relevant studies on marble [7, 17] and porous stone of Kefalonia, Greece [18] has paved the way for this particular investigation comprising an experimental protocol of three-point bending tests, aiming at shedding light on the dependence of flexural strength, deflection at mid-span, crack mouth opening displacement and fracture energy on specimen size and shape. This is a contribution to the wider investigation of the problem but also of applicability for the optimization of the design and rehabilitation of load-bearing structural members like lintels and sills, loaded in position in a similar way.

\section{THE EXPERIMENTAL PROTOCOL}

\section{The materials}

wo natural building stones widely used in Edinburgh were selected for the first stage of this experimental study: 'Grove Whitbed' Portland limestone and Corsehill sandstone.

Portland limestone, originating from the Jurassic Period, is a grain supported biomicrite consisting of rounded micritic ooliths with concentric structures of diameters ranging from $50 \mu \mathrm{m}$ to $300 \mu \mathrm{m}$, irregular quartz grains with a nominal size of $100 \mu \mathrm{m}$ and a large quantity of bioclasts which range in size from $5 \mu \mathrm{m}$ to $20 \mu \mathrm{m}$ [19]. The relatively large Turreted Gastropods (fossilised shells) and clam shells found within Portland limestone are responsible for the voids (nominal size of $100 \mu \mathrm{m}$ ) that can be found throughout the stone, as the removal of these shell fragments due to percolating rain over time left behind what can be observed as holes. Portland limestone has a creamy/white hue, which can be darkened by clusters of grey shell fragments, scattered throughout the stone. It has a coarse texture and inhomogeneous/porous properties, which contributes to the stone having a low level of durability, with a weathering rate of 3 mm to $4 \mathrm{~mm}$ per 100 years expected, particularly at the edges of stonework [19]. In construction projects, Portland limestone has been successfully used for load-bearing units as well as cladding.

Corsehill Sandstone is a fine-grained, pale red-brown, somewhat calcareous sandstone originating from the Triassic Period. Its petrographic content comprises of detrital quartz, opaline silica, feldspars and occasional mica crystals which all have a reddish hue due to a ferruginous clay coating. There is a vast quantity of iron minerals, as both black and brown haematite are present in the sandstone. The rock fragments within the sandstone comprise mostly of polycrystalline chert and mudstone grains. Occasionally, samples display altered quartz grains with iron oxide in the pore spaces. Samples that have a coarser texture are usually less altered, with a larger presence of silica cement [19].

Corsehill Sandstone is a durable sandstone that has been used for many applications in construction projects, such as cladding, paving and load-bearing units. It has a high resistance to air pollution and acid rain; however, it has a poor resistance to salt damage, meaning its suitability for use in harsh coastal environments could be called into question [19]. 
Comparative study: the specimens and the experimental set-up

Within the scope of this comparative study, the experimental investigation comprised a series of non-destructive (N-D) tests for the determination of the apparent density, real density, open porosity, total porosity and sound speed propagation for each material, as well as destructive testing for the determination of their compressive strength and flexural strength under concentrated load or constant moment. A range of prismatic samples (Fig.3), compliant to the specifications of the relevant standards, was cut as per the following schematic representation (Fig.4a) for the bending tests, with some of them carrying a central machined notch, $3.5 \mathrm{~mm}$ wide. More specifically, a series of both $3 \mathrm{~PB}$ and $4 \mathrm{~PB}$ tests were performed on three types of Corsehill sandstone specimens, with three repetitions each: specimens bearing no notch and specimens bearing a $10 \mathrm{~mm}$ or $20 \mathrm{~mm}$ long notch. The significant inhomogeneity of Portland limestone as well as the easier access to it for testing purposes, supported a decision for a more detailed experimental investigation for this material, based though on the same principles. A series of both $3 \mathrm{~PB}$ and $4 \mathrm{~PB}$ tests were performed on six types of Portland limestone specimens, with three repetitions each: specimens bearing no notch and specimens bearing a $5 \mathrm{~mm}, 10 \mathrm{~mm}, 15 \mathrm{~mm}$ or $20 \mathrm{~mm}$ long notch. Quasi-cubic specimens (Fig.4b) were used for all other types of tests, with three repetitions each.

(a)

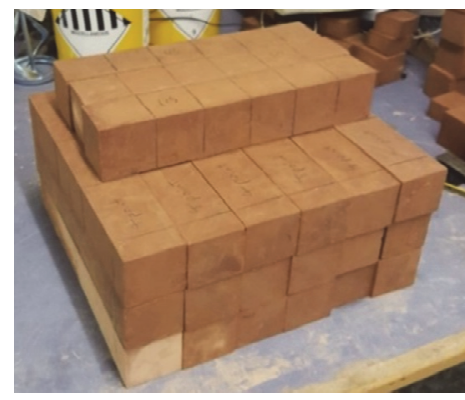

(b)

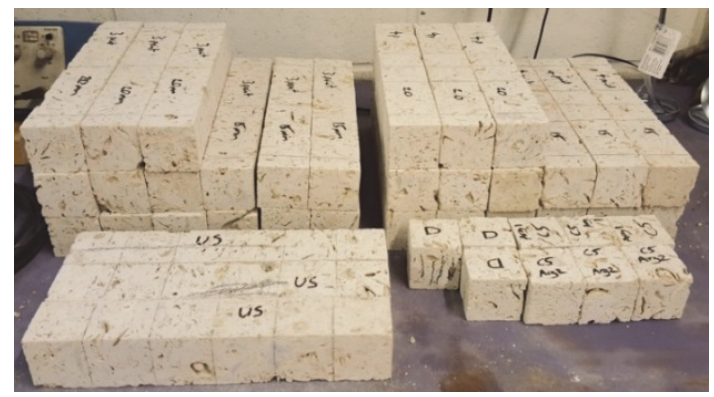

Figure 3: (a) Corsehill sandstone and (b) Portland limestone specimens.

(a)

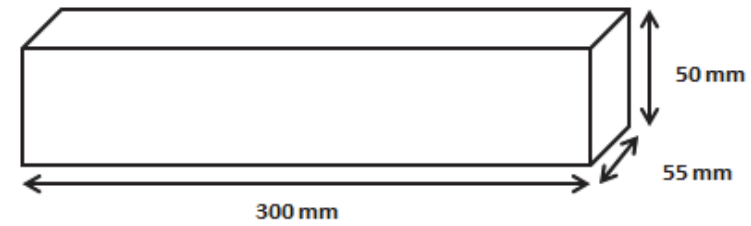

(b)

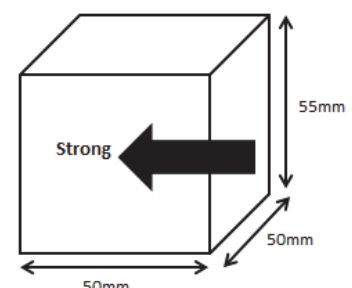

Figure 4: Dimensions for typical prismatic specimens for (a) bending tests and (b) compression and N-D tests.

All experimental work took place at the 'Heavy Structures' laboratory, Edinburgh Napier University. The determination of apparent density, real density, open porosity and total porosity was carried out in accordance with BS EN1936: 2006, making use of an evacuation vessel which can maintain a pressure of $2 \pm 0.7 \mathrm{kPa}$ while providing gradual submersion of a test specimen, and a scale with an accuracy of $0.01 \%$ which is also capable of operating while submerged in water. The determination of sound speed propagation was carried out in accordance with BS EN 14579: 2004, making use of an electrical pulse generator, a pair of transducers, an amplifier and an electronic timing device capable of measuring the time taken for the transmitted pulse to reach the receiving transducer. For performing these non-destructive tests, a ventilated oven capable of maintaining a temperature of $70 \pm 5{ }^{\circ} \mathrm{C}$, a room maintained at a temperature of $20 \pm 1{ }^{0} \mathrm{C}$ and a linear measuring device with an accuracy of $0.05 \mathrm{~mm}$ were used as needed, per the standards' requirements.

Both 3PB and 4PB tests (Fig.5), following BS EN 12372: 2006 (Natural stone test methods - Determination of flexural strength under concentrated load) and BS EN 13161: 2008 (Natural stone test methods - Determination of flexural strength under constant moment) respectively, were carried out to determine the flexural strength of Corsehill sandstone and Portland limestone under varying conditions. Using the principles discussed in ASTM E399-90 (Standard test method of plane-strain fracture toughness of metallic materials), machined notches of varying sizes as previously described, were made on the samples. However, some of the requirements of the above standard cannot be fulfilled for stone, while other size conditions can only be tested after the results have been obtained, hence promoting the trial-validating testing procedure. The direct scope of these bending tests was the collection of data in order to determine the relationship between the external loading and crack opening displacement (COD) and the dependence of COD on the relative dimensions of the notch with respect to the size of the specimens as well as the method of its determination. 

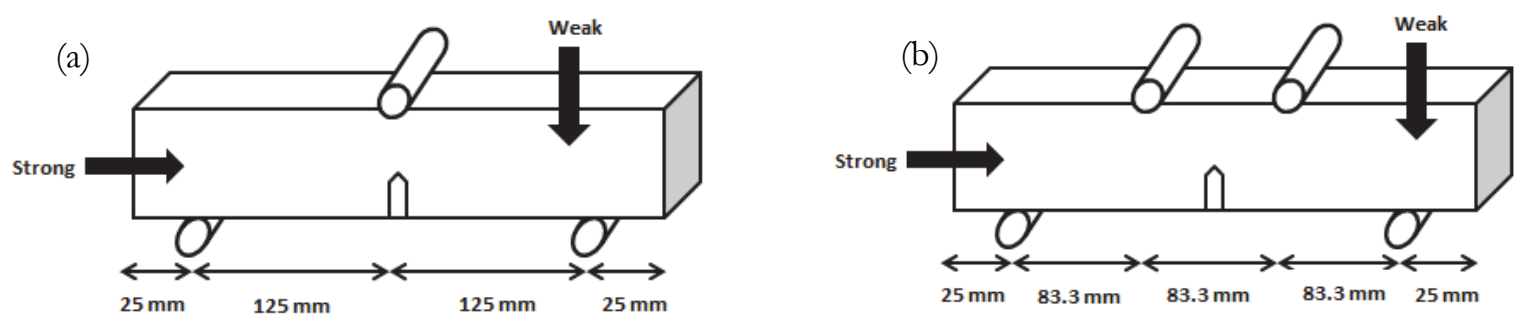

Figure 5: Configuration of specimens for (a) $3 \mathrm{~PB}$ and (b) $4 \mathrm{~PB}$ tests.

It is assumed that the longitudinal axis of the specimens coincides with the strong anisotropy direction of the material. Testing then took place using a stiff Instron Universal testing machine calibrated to EN12390 and the bending load was applied uniformly along the thickness of the specimens with the aid of one or two identical steel rollers. Appropriately positioned Linear Variable Differential Transformers (LVDTs) were used to capture deflections at mid-span (Fig.6a) and CMOD was measured with a special clip gauge supported by a pair of machined knife edges glued to either side (Fig.6b). Both $3 \mathrm{~PB}$ and $4 \mathrm{~PB}$ tests were carried out for comparison purposes, to check the independence of the critical COD from the method used for its determination. Specimens of the same dimensions were tested with notches of various lengths to study the influence of the size (notch length) on the magnitude of the critical COD. Using the same testing machine and loading controlled by the displacement of the hydraulic jack, the compressive strength for both materials was determined following BS EN 1926: 2006 (Natural stone test methods - Determination of uniaxial compressive strength) (Fig.6c).
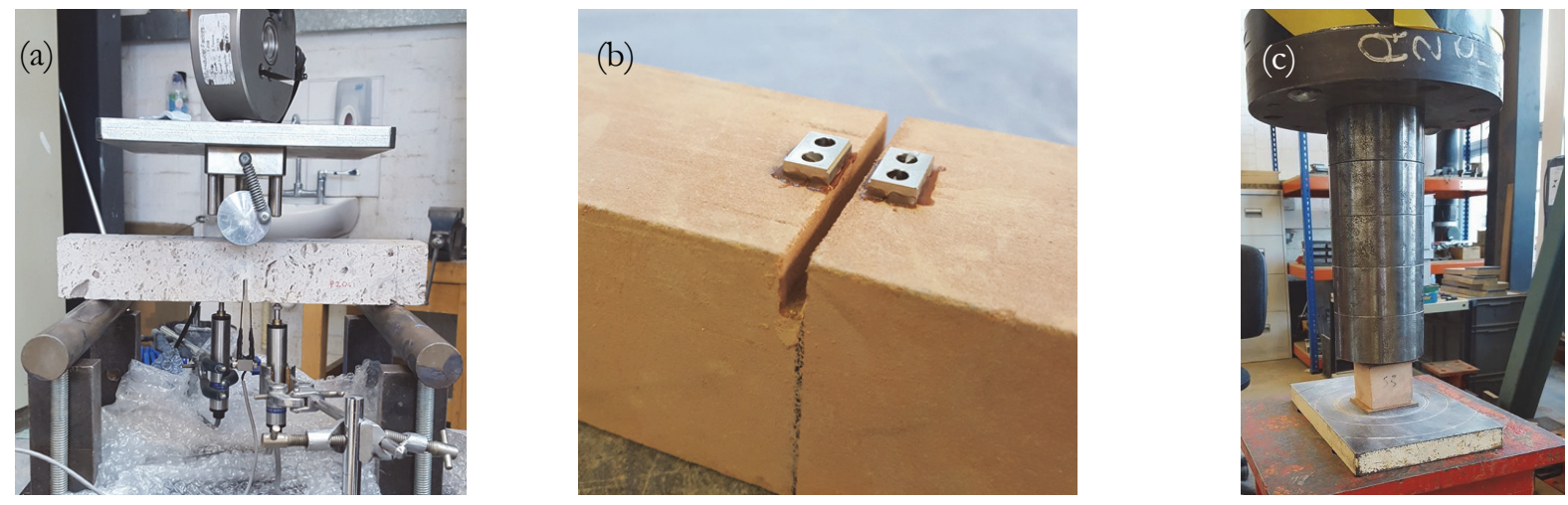

Figure 6: (a) A typical 3PB test with measuring equipment; (b) support for the clip gauge measuring CMOD; (c) typical compression test.

\section{Investigating the size-and shape-effects for Portland limestone: the specimens and the experimental set-up}

Within the scope of this paper, the second stage of experimental investigation aiming at investigating the size- and shapeeffects for Portland limestone, comprised 3PB tests on specimens with span/depth ratios of 5/2, 4 and 6 , bearing a 4 mm wide machined notch at their mid-span for $1 / 3$ of their depth. For each span/depth ratio and a constant breadth of $40 \mathrm{~mm}$, three different sizes of specimen (span length $=200 \mathrm{~mm}, 400 \mathrm{~mm}$ and $800 \mathrm{~mm}$ ) were tested, with four repetitions each, in order to observe the influence of size as well as shape on flexural strength, deflection at mid-span, CMOD and fracture energy. The type of test and specimens' dimensions adopted (Table 1) were based on considerations of appropriate standards and publications [20,21] and limitations regarding laboratory facilities and costs.

The experimental protocol implemented for this stage followed the principles described in BS EN 12372: 2006 (Natural stone test methods - Determination of flexural strength under concentrated load) and by RILEM Technical Committee $50-F M C ~[20]$. The specimens were left to dry in a ventilated oven at $70 \pm 5 \circ \mathrm{C}$ until a constant mass was achieved and then were stored at $20 \pm 5{ }^{\circ} \mathrm{C}$ to reach thermal equilibrium. Testing took place within 24 hours, using the same stiff Instron Universal testing machine calibrated to EN12390 and in configuration as per Fig.7, having the specimen's strong plane of anisotropy perpendicular to the direction of the applied load.

A clip gauge was again positioned across the notch on the specimen, to record the CMOD. Appropriately positioned LVDTs were used to capture deflections at mid-span. Adopting a displacement-control procedure at testing, the loading rate applied was $0.1 \mathrm{~mm} / \mathrm{min}$. Following this, the peak load was reached within approximately 2-3 minutes and, given our interest in the post-peak behaviour of the material till the specimen can bear no load, the duration of each test was 8-10 minutes. 


\begin{tabular}{ccccc}
\hline Span/Depth Ratio & Length $(\mathrm{mm})$ & Span $(\mathrm{mm})$ & Depth $(\mathrm{mm})$ & Notch length $(\mathrm{mm})$ \\
& 250 & 200 & 80 & 27 \\
$5 / 2$ & 450 & 400 & 160 & 53 \\
& 850 & 800 & 320 & 160 \\
\hline \multirow{3}{*}{4} & 250 & 200 & 50 & 17 \\
& 450 & 400 & 100 & 33 \\
& 850 & 800 & 200 & 67 \\
\hline \multirow{2}{*}{6} & 250 & 200 & 33 & 11 \\
& 450 & 400 & 66 & 44 \\
\hline
\end{tabular}

Table 1: Second stage of experimental investigation - Portland limestone test specimen specifications.
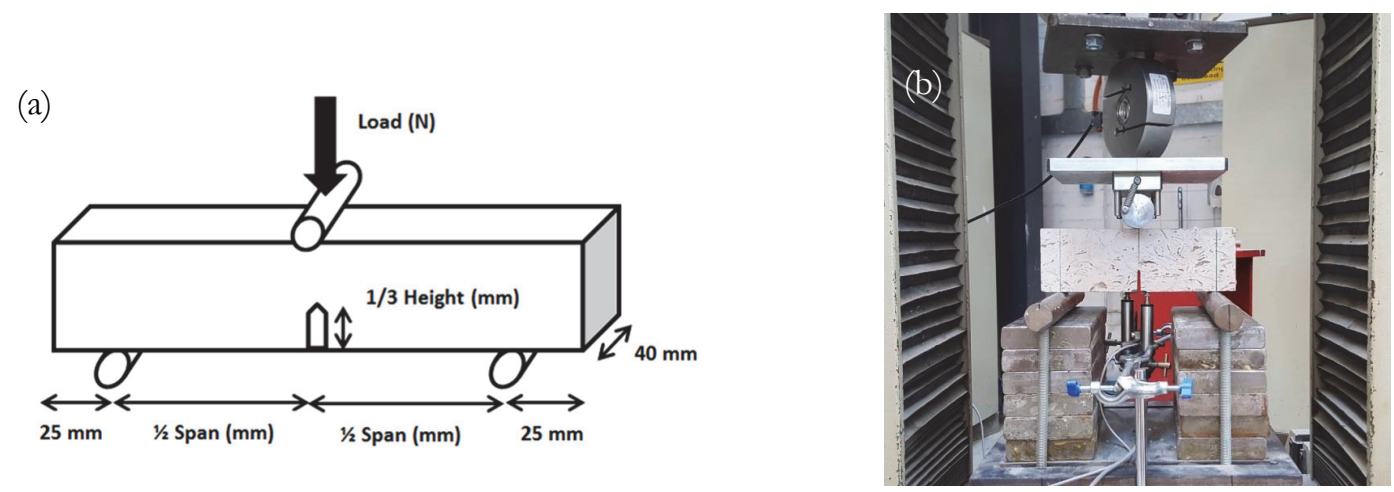

Figure 7: (a) Three-point bending test configuration; (b) actual test set-up (200 mm span).

\section{EXPERIMENTAL RESULTS}

\section{Comparative study: material characterization and combined results}

B ased on non-destructive testing results as described above, average values of fundamental material properties were derived for both Portland limestone and Corsehill sandstone (Table 2), after 3 repetitions of each type of test. As expected, given the highly inhomogeneous and porous nature of Portland limestone, Corsehill sandstone has a greater apparent density than Portland limestone, although Portland limestone has a higher density of solids. The use of an ultrasonic pulse velocity (UPV) test instrument confirms the higher porosity of Portland limestone, as the average velocity of the ultrasonic waves passing through this material's samples is $4.74 \mathrm{~mm} / \mu \mathrm{s}$, significantly higher and presenting also a greater variance compared to the almost stable $2.81 \mathrm{~mm} / \mu \mathrm{s}$ recorded for the more uniform Corsehill sandstone samples. These findings are in good agreement with other data existing in the literature [19].

\begin{tabular}{lcc}
\hline Material properties & Portland limestone & Corsehill sandstone \\
Apparent Density $\left(\mathrm{kg} / \mathrm{m}^{3}\right)$ & 1955.14 & 2279.91 \\
Density of solids $\left(\mathrm{kg} / \mathrm{m}^{3}\right)$ & 3078.42 & 2493.79 \\
Open Porosity $(\%)$ & 15.87 & 7.94 \\
Total Porosity $(\%)$ & 36.49 & 8.58 \\
Modulus of Elasticity (3PB) (MPa) & 8340.54 & 2884.45 \\
Modulus of Elasticity (Pundit) & 11820.89 & 4778.48 \\
Compressive Strength (MPa) & 36.90 & 37.93 \\
Flexural Strength (3PB) (MPa) & 4.91 & 5.43 \\
Flexural Strength (4PB) (MPa) & 4.13 & 5.43 \\
\hline
\end{tabular}

Table 2: Comparison of fundamental material properties for Portland limestone and Corsehill sandstone. 
Average results from 3 compressive tests per material appear in Table 2 as well, with the note that only tests exhibiting a satisfactory failure mode were included (Fig.8). Observing the failure modes of all specimens for 3PB and 4PB tests, it is to be noted that Corsehill sandstone samples failed following a more regular and predictable pattern than the Portland limestone ones (Fig.9). As the machined notch lengths increased, the failure modes became more uniform across the board. The irregularity of the failure modes of the Portland limestone samples can be partly explained by the presence of relatively large mineral build-ups inside the samples, which promote failure planes around them (Fig.10). Once failed, these mineral build-ups resemble a ball and socket joint.
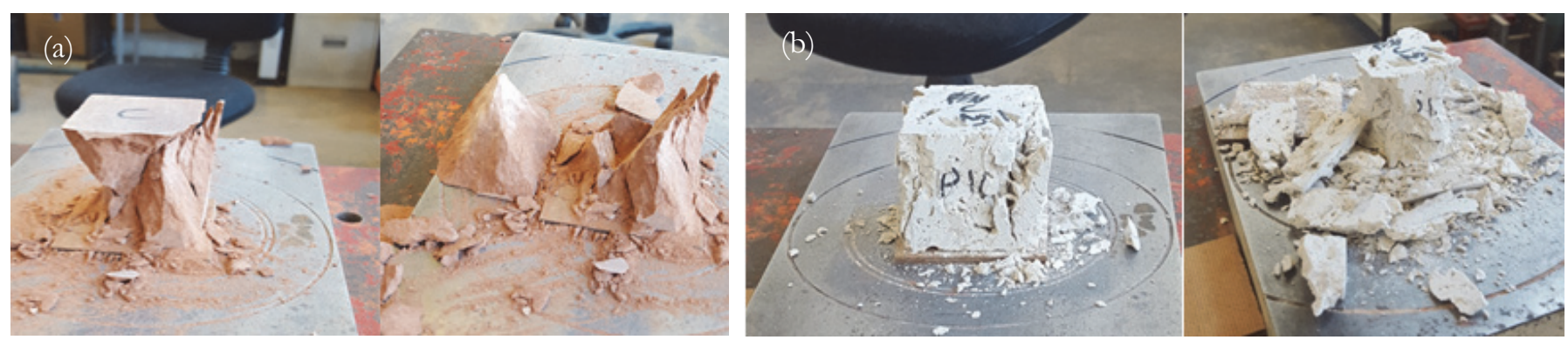

Figure 8: Specimens with uniform failure modes in compression, for (a) Corsehill sandstone and (b) Portland limestone.
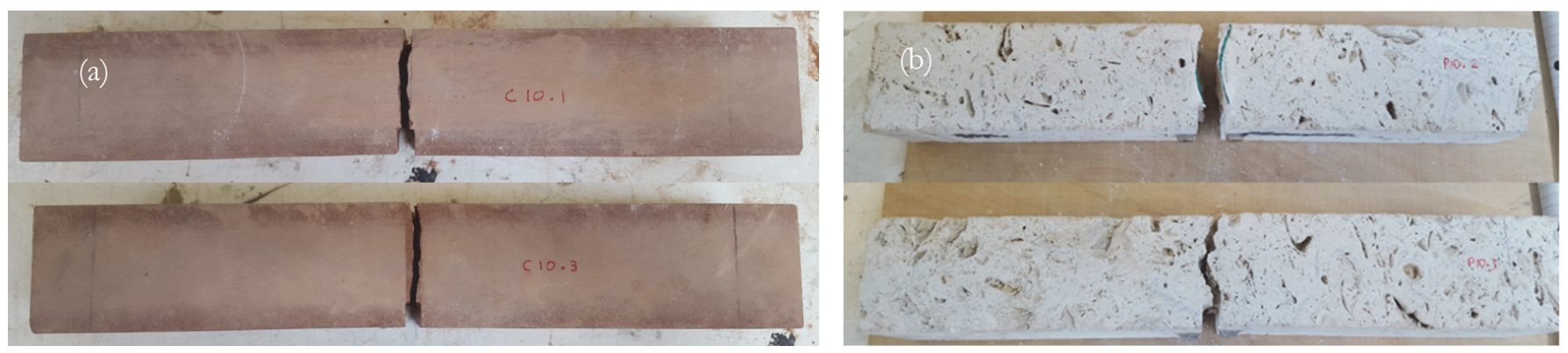

Figure 9: 3PB specimens with a 10mm notch, post-testing, for (a) Corsehill sandstone (b) Portland limestone.

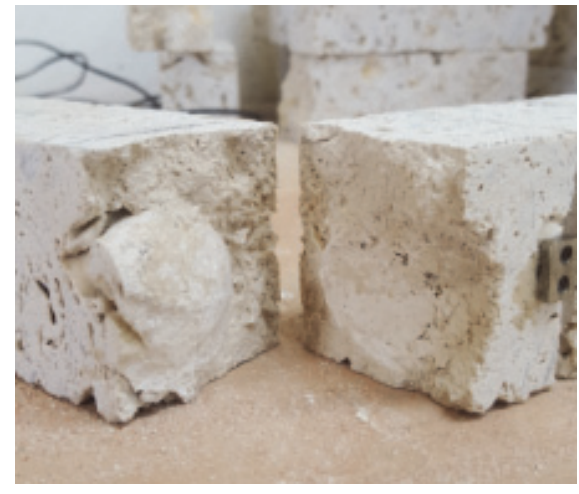

Figure 10: Failure around a mineral build-up (Portland limestone).

For both $3 \mathrm{~PB}$ and $4 \mathrm{~PB}$ tests, the complete series of measurements is available in terms of measured CMOD and deflection at mid-span versus load. Some measurements are inevitably affected by local inhomogeneity characterizing natural building stones, however the trend can be seen: the deeper the notch, the non-linearity is more pronounced for load levels approaching the ultimate load (Fig.11).

The two stone types were ultimately compared through key parameters such as flexural strength, displacement at the midspan and CMOD both at peak load, against the ratio of the test specimen height to the length of the existing machined notch. Flexural strength is defined according to the classical theory of Mechanics as $f_{u}=M / w$ ( $M$ the bending moment and $\mathrm{w}$ the section modulus). For the average of measured values for each testing category, elaborated data are presented towards the scope of introducing an easy-to-use in practical applications fracture criterion. The variation of the flexural strength (average of ultimate stresses as defined previously) for $4 \mathrm{~PB}$ tests versus the ratio a/h (notch length/specimen 
height) is presented in comparison with the corresponding results from 3PB tests for both materials (Fig.12a). The flexural strength becomes less varied for an $\mathrm{a} / \mathrm{h}$ ratio greater than 0.2 while for insignificant notch length the strength increases, tending to that of the intact specimen.

As shown in Fig.12b, intact specimens of Corsehill sandstone have a significantly higher maximum deflection at mid-span just before failure when compared with Portland limestone. With the introduction of a notch though, the maximum deflection of the Corsehill sandstone specimens drops dramatically, while the maximum deflection of the Portland limestone specimens presents a less pronounced, gradual decrease. It is worth noting however that when the notch length is $20 \mathrm{~mm}$, both Corsehill sandstone and Portland limestone appear to be tending towards a critical deflection at mid-span. Given the maximum load levels achieved by the two materials and as Corsehill sandstone presents generally clearly higher maximum deflections than Portland limestone when un-notched, the former appears to have a less brittle behaviour than the latter.
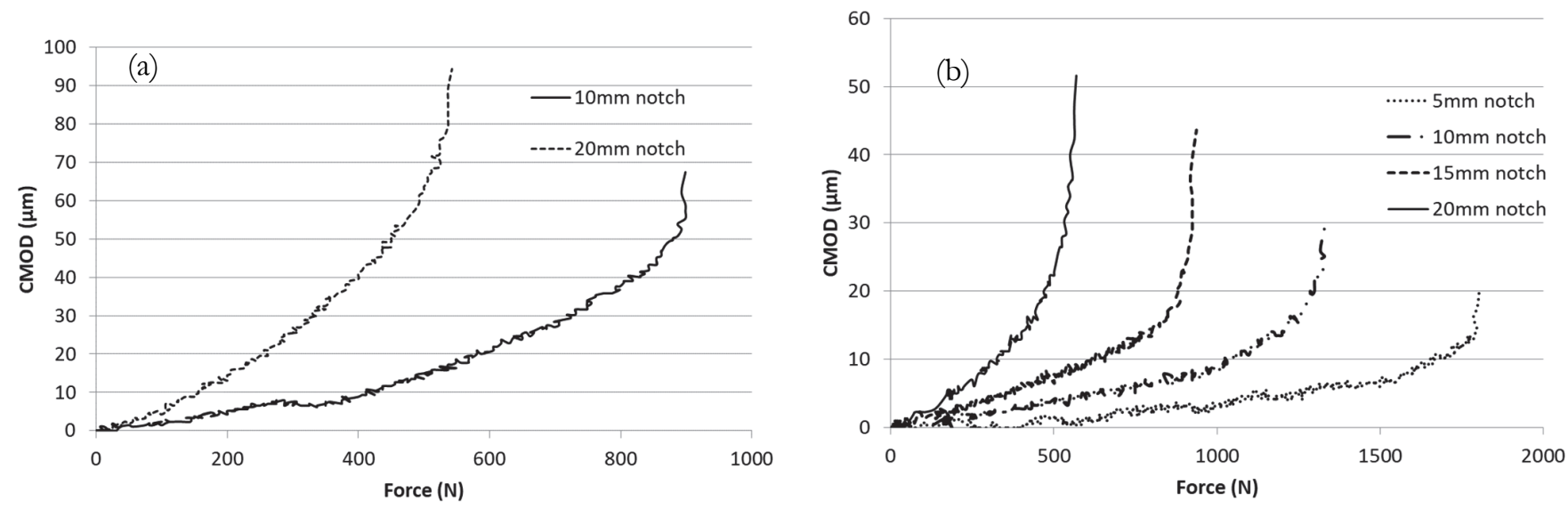

Figure 11: (a) Graph of CMOD against force (Corsehill Sandstone 3PB) (b) Graph of CMOD against force (Portland limestone 3PB).
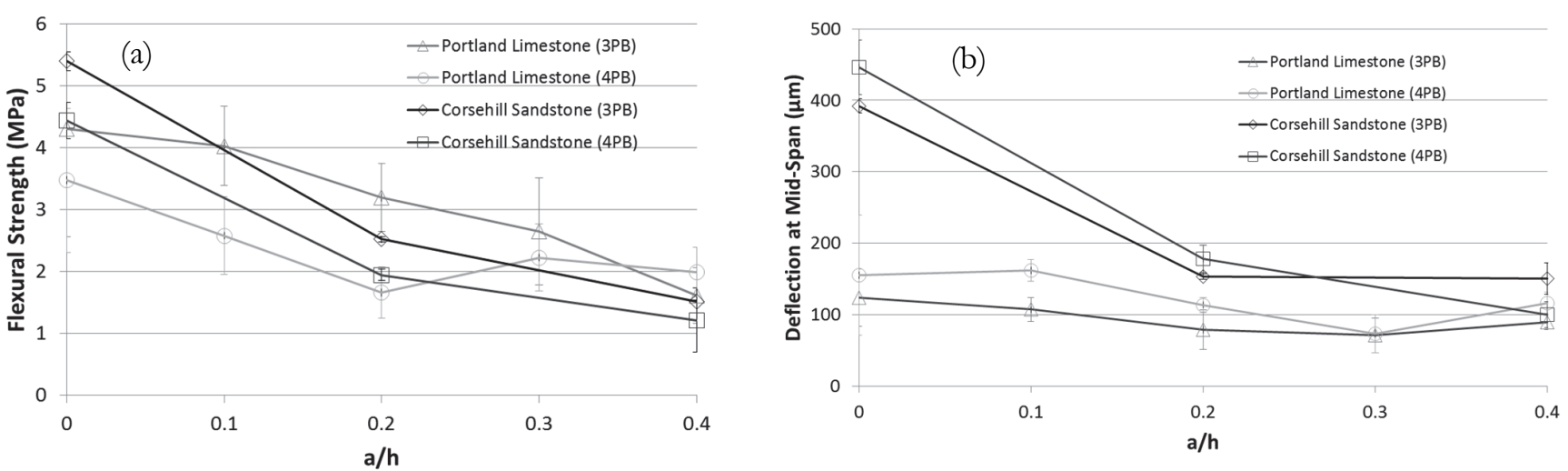

Figure 12: Graphical representation of average values \pm STDEV for (a) Flexural strength vs. \{notch length/specimen height and (b) Deflection at mid-span vs. \{notch length/specimen height\}, for both types of test and materials.

During the tests, COD is measured at the notch mouth but for the sake of uniformity and in order to eliminate the dependence from the notch length, a reference length $a_{\text {ref }}$ is introduced where the critical COD is defined (Fig.13a). The measured value of CMOD is recalculated as COD according to linear proportion (assuming the flanks remain linear) and then the normalized value $\delta$ can be introduced. For the determination of $\delta_{\text {crit }}$ the selection of $a_{\text {ref }}=0.1 \mathrm{~cm}$ as a reference length was made. The parameter $\delta_{\text {crit }}$ is plotted against the ratio a/h for both materials and types of tests and comparison reveals a similar behaviour characterised by decreasing values. Especially for Portland limestone for which more experimental data exist, a tendency towards a constant $\delta_{\text {crit }}$ for the presence of a notch of significant length is observed (Fig.13b).

Fracture criteria based on COD and $f_{u}$ are alternative expressions of the same natural concepts since there are analytical formulas relating these parameters to each other, especially for brittle materials. For this part of the investigation, the dependence of COD on the specimen height is covered by the study of the behaviour with reference to the ratio a/h. There is also dependence on the specimen thickness but for thick specimens, plane strain conditions are assumed and the COD values become stable. In any case and form, the criterion implied here as a single value (lower limit) based on a limited 
number of tests, is a reduced form of a 3-dimensional approach depending on the notch inclination and the anisotropy direction of the material with respect to the specimen geometry.
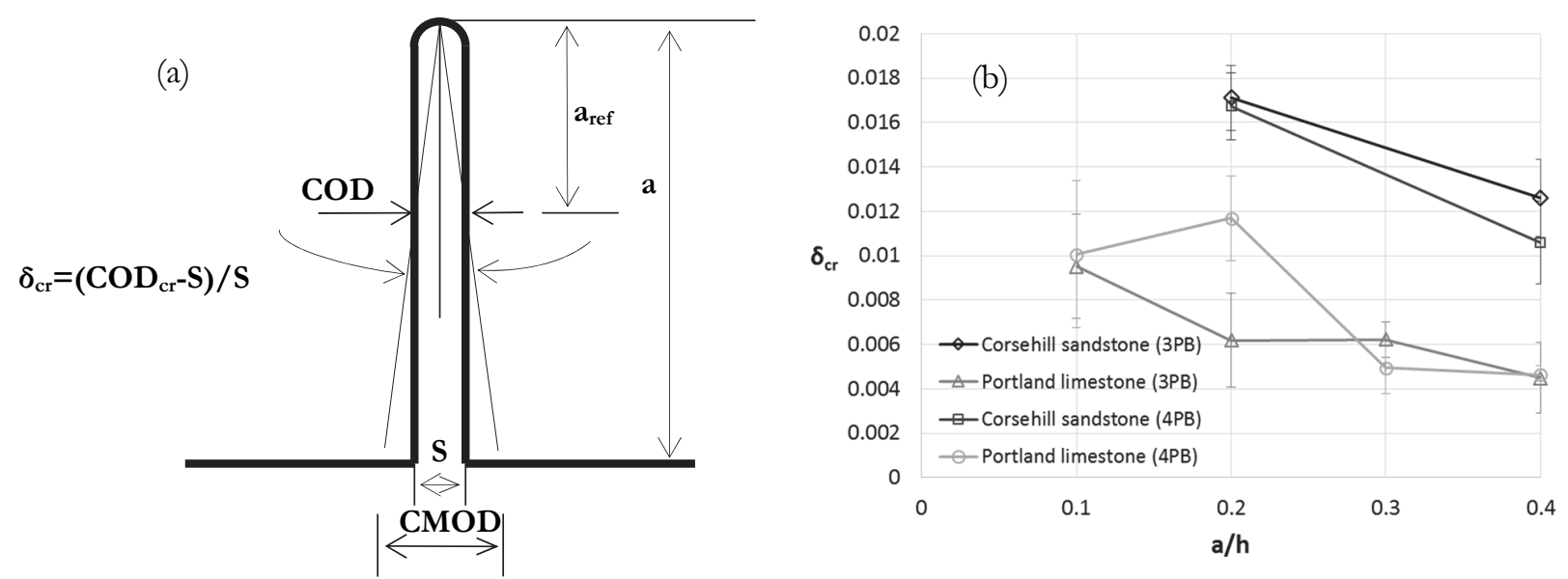

Figure 13: (a) Definition of the critical COD and $\delta$, as functions of the CMOD, (b) Graphical representation of average $\delta_{\mathrm{cr}} \pm$ STDEV vs. $\{$ notch length/specimen height\}, for both types of test and materials.

\section{An insight into the fracture behaviour of Portland limestone: the size- and shape-effects}

Based on the results obtained by the comparative study presented above, and given the inhomogeneous nature of Portland limestone and the wide range of projects in which this material is involved in Edinburgh, a second phase of this experimental investigation aimed at enhancing understanding of the structural behaviour of this natural building stone through examination of possible size- and shape-effects. Typical load-deflection at midspan and load-CMOD curves of Portland limestone specimens under 3PB were directly derived from experimental recordings (Fig.14). A typical loaddeflection curve consists of three distinct portions: up to the peak load the constitutive law is almost perfectly linear elastic. This region is abruptly terminated by a significant load drop, which in turn leads to a third portion, characterized by a small slope, up to the final disintegration of the specimens.
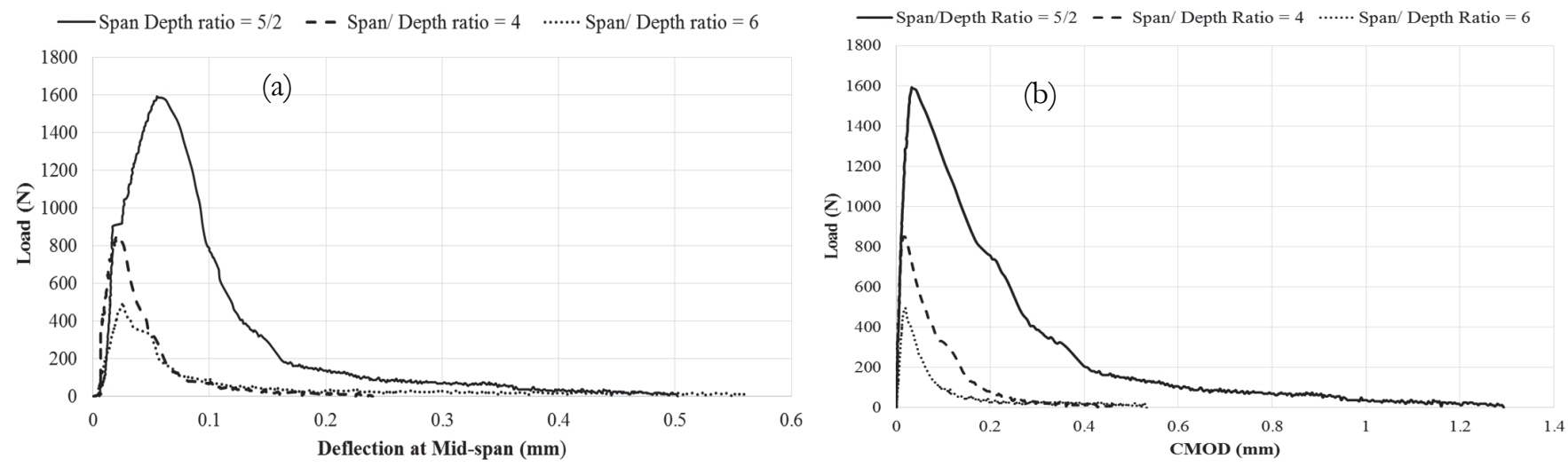

Figure 14: (a) Applied load vs. deflection at mid-span for 200 mm spans; (b) Applied load vs. CMOD for 200 mm spans.

Using concepts developed for concrete but applicable to other materials where the compressive strength is high compared to the tensile strength, Portland limestone's toughness and subsequently tensile fracture behaviour were quantified by means of calculating the fracture energy per unit area of the fracture surface, $G_{F}$. The fracture energy can be determined by means of a stable bending test, provided that the fracture takes place along one reasonably well-defined plane and that energy absorption in other processes than tensile fracture is negligible [21]. Considering the area $\mathrm{W}_{0}$ below a 'loaddeflection at midspan' diagram that gives the energy supplied by the machine and making a correction for the amount of absorbed energy due to the weight of the beam/testing equipment between the supports, the fracture energy per unit area is calculated as: 


$$
G_{F}=\frac{W_{0}+m g \cdot \delta_{0}}{A_{\operatorname{lig}}}
$$

where $\delta_{o}$ is the deformation when the force has fallen to zero and $A_{\text {lig }}$ is the projection of the fracture area on a plane perpendicular to the beam axis (ligament area). The summary of average results for parameters as outlined above is presented in Table 3:

\begin{tabular}{cccccc}
\hline $\begin{array}{c}\text { Span/ Depth } \\
\text { Ratio }\end{array}$ & $\begin{array}{c}\text { Span } \\
(\mathrm{mm})\end{array}$ & $\begin{array}{c}\text { Fracture Energy } \\
\left(\mathrm{Nm} / \mathrm{m}^{2}\right)\end{array}$ & $\begin{array}{c}\text { Flexural Strength } \\
(\mathrm{MPa})\end{array}$ & $\begin{array}{c}\text { Deflection at Peak Load } \\
(\mathrm{mm})\end{array}$ & $\begin{array}{c}\text { CMOD at Peak Load } \\
(\mathrm{mm})\end{array}$ \\
5 & 200 & 67.46 & 1.89 & 0.042 & 0.039 \\
$5 / 2$ & 400 & 95.30 & 1.76 & 0.103 & 0.066 \\
& 800 & 284.33 & 1.08 & 0.750 & 0.104 \\
\hline \multirow{3}{*}{4} & 200 & 36.45 & 2.37 & 0.076 & 0.043 \\
& 400 & 40.12 & 1.84 & 0.076 & 0.043 \\
& 800 & 152.45 & 1.48 & 0.446 & 0.085 \\
\hline 6 & 200 & 37.78 & 3.18 & 0.028 & 0.021 \\
& 400 & 49.27 & 1.82 & 0.089 & 0.029 \\
\hline
\end{tabular}

Table 3: Summary of three-point bending tests results for Portland limestone.

Completing the testing program as detailed in the section presenting the experimental protocol, led to observations on average results regarding the influence of the specimens' geometry on key properties such as the deflection at mid-span and the CMOD at peak load, the flexural strength, the fracture energy and potential failure modes. For all three sets of span/depth ratios, there is a steep increase in deflections when the specimen span length increases to $800 \mathrm{~mm}$. The magnitude of this increased rate of deflection at mid-span increases as the test specimen's span/depth ratio decreases (Fig. 15a). In terms of CMOD, apart from the case of a span/depth ratio equal to 4 with span lengths of $200 \mathrm{~mm}$ and $400 \mathrm{~mm}$, where values remained constant, in general it was observed that CMOD values increase at an almost uniform rate as their span length increased (Fig.15b). Larger values of CMOD were recorded as the span/depth ratio decreased.

In terms of flexural strength, the span/depth ratio, which appears to be most sensitive to changes in size, is the largest, 6 . The test specimens with span/depth ratios of 5/2 and 4 present very similar outcomes to each other, which is the case also for the span/depth being 6, with span lengths $400 \mathrm{~mm}$ and $800 \mathrm{~mm}$ (Fig.16a). The values of fracture energy obtained from test specimens with span/depth ratios of 4 and 6 are very similar for spans $200 \mathrm{~mm}$ and $400 \mathrm{~mm}$ while those for span/depth ratio of 5/2 are significantly larger (Fig.16b). Values of fracture energy for all span/depth ratios increase as test specimen size increases but particularly those of 5/2 and 4 appear to increase at a higher rate for spans above $400 \mathrm{~mm}$. These findings are in good agreement with data existing in the literature, stating that fracture energy is directly influenced by the configuration of the test specimens [22].
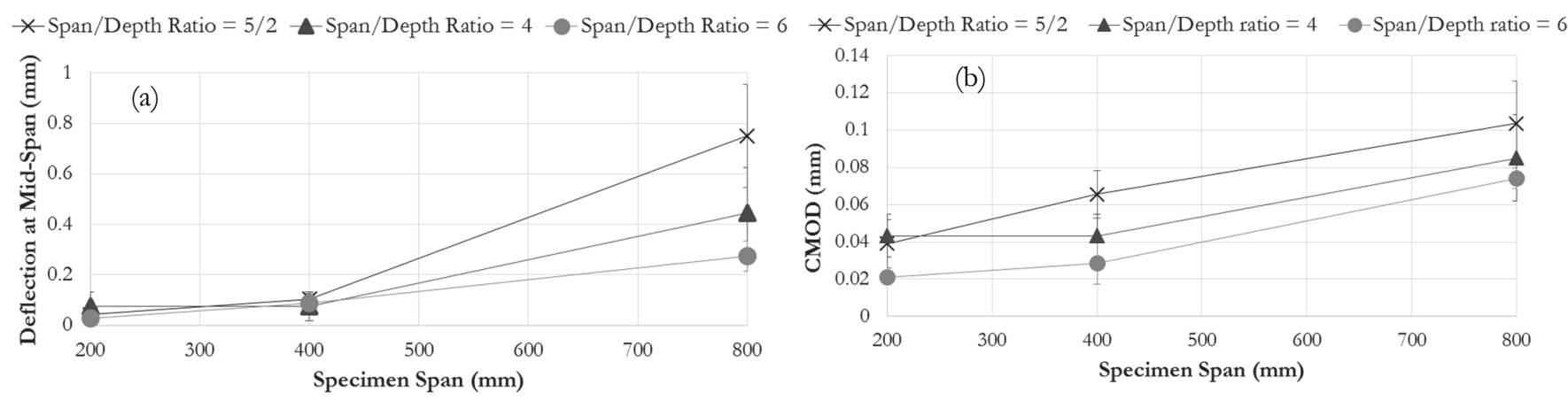

Figure 15: Average values \pm STDEV for (a) Deflection at mid-span vs. span length for all span/depth ratios; (b) CMOD vs. span length for all span/depth ratios. 

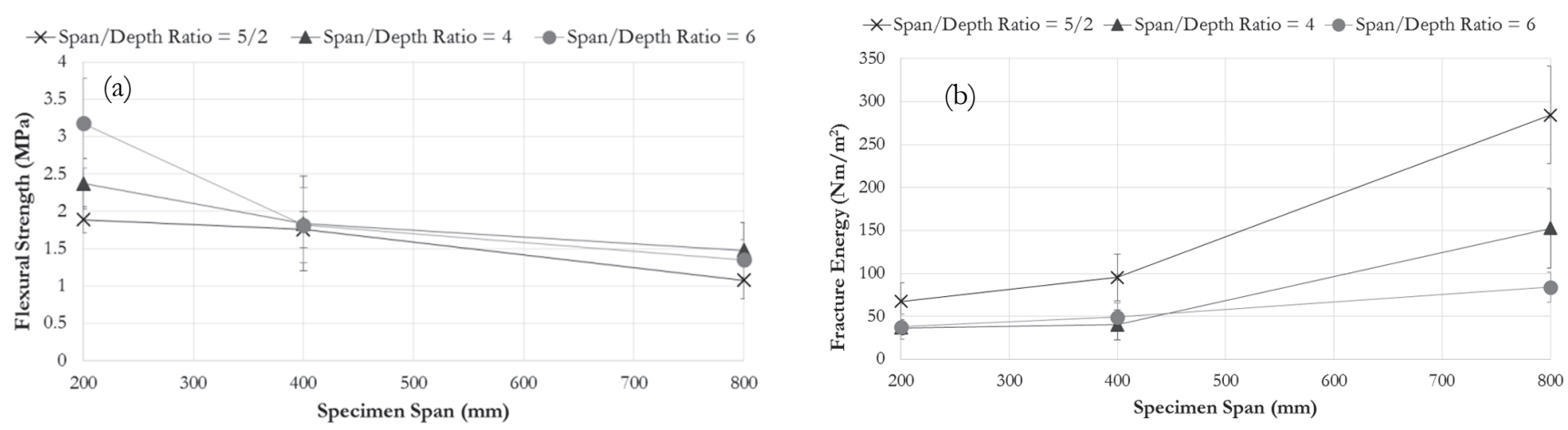

Figure 16: Average values \pm STDEV for (a) Flexural strength vs. span length for all span/depth ratios; (b) Fracture energy vs. span length for all span/depth ratios.

Most of the specimens failed in a similar manner for all shapes, with cracks appearing to propagate from the tip of the notch and then veering slightly off-center. With the span/depth ratio of 6 , there were occasions when the specimens failed off-center, with the crack starting at a random location between the notch and roller supports. Most irregular failure modes observed were again attributed post-failure to the presence of relatively large mineral build-ups (Fig.10).

\section{DISCUSSION AND CONCLUSIONS}

he development of suitable methodologies of experimental investigation for two natural building stones used widely in construction projects in Edinburgh was approached through an experimental study comprising both non-destructive (for apparent density, real density, open porosity, total porosity and sound speed propagation) and destructive testing (for compressive and flexural strengths). Fundamental mechanical properties for Corsehill sandstone and Portland limestone were derived, compared and contrasted, with the intention to point out characteristic behaviour patterns of applicability especially to restoration projects.

From the study on the fracture resistance of prismatic specimens carrying machined notches of different lengths, and following data processing and interpretation of the results, it seems that the critical COD under specific conditions could be further investigated as a fracture criterion, independently of the method used for its determination. After a critical limit, it is the presence of the notch itself that plays a crucial role and not its relative length.

Alternative expressions for one-dimensional fracture criteria (a single point - critical value - in the space of a criterion with parameters: $\delta_{\text {crit }}$ angle of notch inclination and angle of anisotropy direction) have been proposed as functions of stresses and $\delta_{\text {crit. }}$ Such an approach based on a single geometry does not allow for general conclusions although it seems that a criterion based on stresses is relatively stable and convenient for engineering applications.

The further objective of this research was to examine the effect that test specimen size and shape have on several key properties of Portland limestone, including deflection at mid-span at peak load, CMOD at peak load, flexural strength and, in particular, fracture energy. For the specimens tested in 3PB, containing three different shapes (span over depth ratio) that came in three different sizes (spans), the relationship between the studied deflection and specimen span length was identified for span/depth ratios of 5/2 and 4, characterised by a gentle positive gradient existing between span lengths of $200 \mathrm{~mm}$ and $400 \mathrm{~mm}$, before a dramatic increase between span lengths of $400 \mathrm{~mm}$ and $800 \mathrm{~mm}$. For test specimens with a span/depth ratio of 6 , this deflection appeared to increase linearly with span length. It was also observed that the deflection seemed independent of the span/depth ratio of the specimens for span lengths $200 \mathrm{~mm}$ and $400 \mathrm{~mm}$ but for span lengths $800 \mathrm{~mm}$, it increased as the span/depth ratio decreased. A similar pattern of observations was made for the CMOD at peak load, leading to the conclusion that it appears likely for a critical specimen size to exist for Portland limestone, where the effect of specimen size and shape becomes more apparent.

A negative correlation between the flexural strength of Portland limestone specimens and their span lengths for all three shapes was observed, supporting previous findings [23]. This was most evident for span/depth ratio of 6 , with a significant decrease in flexural strength recorded between the span lengths of $200 \mathrm{~mm}$ and $400 \mathrm{~mm}$.

An important finding of this experimental study was the positive correlation between fracture energy and test specimen size. Between span lengths of $200 \mathrm{~mm}$ and $400 \mathrm{~mm}$ there is a gradual increase of fracture energy, before a significant rise when the span length gets to $800 \mathrm{~mm}$. For the span/depth ratio of 5/2, clearly larger values of fracture energy were recorded, indicating the dependence of fracture energy on test specimen size and geometry as supported by other studies [22]. 
For tests performed within the scope of this investigation, the variation of the strength and fracture energy with increasing specimen's size appears to be monotonic, a behaviour that is commonly observed for concrete [24] but not necessarily for a selection of other natural building stones [18, 25-29]. Given the significant scattering of results for this kind of natural building stones and the scale limitations for this experimental study, definite conclusions for the size- and shape-effects cannot yet be drawn and further experimental evidence would be required. The above requirement is imperative in an effort to fully explore the behaviour laws covering transition from the scale of 'materials' to that of 'structural members' and choose accordingly specimens that are representative of the material's behaviour and useful for design purposes.

\section{REFERENCES}

[1] Australia ICOMOS (2013). The Burra Charter: The Australia ICOMOS Charter for Places of Cultural Significance. Available at: http://australia.icomos.org/wp-content/uploads/The-Burra-Charter-2013-Adopted-31.10.2013.pdf.

[2] UNESCO World Heritage Committee (2017). The Operational Guidelines for the Implementation of the World Heritage Convention. Available at: http://whc.unesco.org/en/guidelines.

[3] Historic Environment Scotland (2017). Advisory Standards of Conservation and Resilience for the Historic Building Environment in Scotland. Available at: https://www.historicenvironment.scot/archives-and-research/publications.

[4] Fairhurst J., Gillanders R., McMillan A. (1999). Building Stones of Edinburgh, Edinburgh Geological Society (2nd Ed.).

[5] Hyslop E., McMillan A., Maxwell I. (2006). Stone in Scotland, UNESCO Publishing.

[6] Anderson, T.L. (1995). Fracture Mechanics: Fundamentals and Applications. Florida: CRC Press, Inc.

[7] Kourkoulis, S.K., Exadaktylos, G.E., Vardoulakis I. (1999). U-notched Dionysos-Pentelicon marble in three point bending: The effect of nonlinearity, anisotropy and microstructure. Int. J. Fracture; 98(3-4), pp. 369-392. DOI: $10.1023 / \mathrm{A}: 1018614023542$.

[8] Bažant, Z.P. and Yavari, A. (2005). Is the cause of size effect on structural strength fractal or energetic-statistical?. Eng Frac. Mech; 72, pp. 1-31. DOI: 10.1016/j.engfracmech.2004.03.004.

[9] Ravaisson-Mollien, C. ed., (1883). Les Manuscripts de Léonard de Vinci, Transl. in French by Institut de France, 3.

[10] Weston, T. ed., (1730) Galileo, Galilei: Discorsi e Dimostrazioni Matematiche intorno a due Nuove Scienze, Elsevirii, Leiden. English transl., pp.178-181.

[11] Fisher R.A., Tippett L.H.C. (1928). Limiting forms of the frequency distribution of the largest and smallest member of a sample. Proc. Cambridge Philos. Soc. 24, pp. 180-190. DOI: 10.1017/S0305004100015681.

[12] Weibull W. (1939). The phenomenon of rupture in solids. Proc. R. Swed. Inst. Engng Res. (Ing. Akad. Handl. Sweden) 153, pp. 1-55.

[13] Walsh P.F. (1972). Fracture of plain concrete. Indian Concr. J. 46(11), pp. 469-70, 476.

[14] Bažant, Z.P. (1984). Size effect in blunt fracture: concrete, rock, metal. J. Eng. Mech. 110, pp.518-535. DOI: 10.1061/(ASCE)0733-9399(1984)110:4(518).

[15] Carpinteri A. (1994). Fractal nature of material microstructure and size effects on apparent mechanical properties. Mech Mater. 18. pp. 89-101. DOI: 10.1016/0167-6636(94)00008-5.

[16] Carpinteri A., Chiaia A., Cornetti P. (2003). On the mechanics of quasi-brittle materials with a fractal microstructure. Eng. Frac. Mech. 70, pp. 2321-2349. DOI: 10.1016/50013-7944(02)00220-5.

[17] Vayas I., Marinelli A., Kourkoulis S.K, Papanicolopulos S.A. (2009). Investigating the Fracture Behaviour of Dionysos Marble: an experimental study. In: Protection of Historical Buildings, II, Mazzolani F.M. (Ed.), A. Balkema Book, Boca Raton, pp. 1699-1704.

[18] Kourkoulis S. K., Ganniari-Papageorgiou E. (2010). Experimental study of the size and shape effects of natural building stones. Construction and Building materials; 24(5), pp. 803-810. DOI: 10.1016/j.conbuildmat.2009.10.027.

[19] Leary E. (1983). The Building Limestones of the British Isles, Building Research Establishment Report, Department of the Environment, UK.

[20] RILEM Technical Committee 50-FMC (1985). Draft Recommendation: Determination of the Fracture Energy of Mortar and Concrete by means of Three-Point Bend Tests on Notched Beams, Materials and Structures 106, pp. 285-290.

[21] Hillerborg A. (1983). Concrete Fracture energy tests performed by 9 laboratories according to a draft RILEM recommendation: Report to RILEM TC50-FMC (Report TVBM; Vol.3015). Division of Building materials, LTH, Lund University. 
[22] Malvar J. and Warren G. (1988). Fracture Energy for Three-Point Bend Tests in Single-Edge Notched Beams. NCEL Technical Report, Naval Civil Engineering Laboratory, Port Hueneme, California.

[23] Rokugo K., Uchida Y., Katoh H, Koyanagi W. (1995). Fracture Mechanics Approach to Evaluation of Flexural Strength of Concrete. ACI Mat J. 92(5), pp. 561-566.

[24] Del Viso J.R., Carmona J.R., Ruiz G. (2008). Shape and size effects on the compressive strength of high strength concrete. Cem. Concr. Res. 38, pp. 386-395. DOI: 10.1016/j.cemconres.2007.09.020.

[25] Kourkoulis S. K. (2011). An Experimental Study of the mechanical behaviour of the 'Conchyliates' Shell-stone: Some irregularities of the Size Effects. Strain 47, pp. 344-356. DOI: 10.1111/j.1475-1305.2009.00618.x.

[26] Vardoulakis I., Kourkoulis S.K. (1997). Mechanical Properties of Dionysos Marble. Final report of the Environment Project EV5V - CT93-0300, National Technical University of Athens, Greece.

[27] Vardoulakis I., Kourkoulis S.K., Exadaktylos G.E., Rosakis A. (2002). Mechanical properties and compatibility of natural building stones of ancient monuments: Dionysos marble. In: Proc of the Intl W/shop: The Building Stone in Monuments, IGME Publishing, Athens: pp. 187-210.

[28] Vardoulakis I. and Kaklis J. (2004). An experimental investigation of the size effect in indirect tensile test on Dionysos marble. In: Proc. of the $7^{\text {th }}$ National Congress on Mechanics (Kounadis et al. Eds). Technical University of Crete Publishing, Chania, Greece,pp. 151-157.

[29] Kourkoulis S. K., Caroni C. and Ganniari-Papageorgiou E. (2005). A contribution to the size effect of natural building stones. In: Proc. Of the $5^{\text {th }}$ GRACM Int. Congress on Comp. Mech., Limassol, Cyprus (Papadrakakis et al. Eds). Kantzilaris Publ, Nicosia, Cyprus, pp. 495-502. 